\title{
One Discount Rate Fits All? The Regressive Effects of DOE's Energy Efficiency Rule
}

\author{
By Sofie E. Miller
}

This paper examines the Department of Energy's (DOE) reliance on low discount rates to estimate the benefits of its energy efficiency standards and uses existing literature on implicit consumer discount rates to calculate a range of benefits for $D O E$ 's furnace fan rule. While DOE calculates large net benefits from its energy efficiency rule, using discount rates that better represent average consumer time preferences shows that this standard results in net costs. Furthermore, given the variation in consumer discount rates by income, this standard is effectively a transfer payment from low- and medianincome households to high-income households.

\section{Introduction}

As a part of its Energy Conservation Program for consumer products, the Department of Energy (DOE) establishes energy efficiency standards for many appliances used daily in American households, such as microwaves, clothes dryers, and air conditioners. DOE receives statutory authority for these rulemakings through the Energy Policy and Conservation Act of 1975 (EPCA), which requires that "any new or amended standard for [covered products] must be designed to achieve the maximum improvement in energy efficiency that is technologically feasible and economically justified" (DOE 2013, 64073). Furthermore, all such stan- dards must result in a "significant" conservation of energy (DOE 2014, 38131). These statutory instructions require a careful analysis of the costs and benefits of DOE's energy efficiency rules.

In July 2014, DOE published a rule that, for the first time, set energy efficiency standards for furnace fans used in residential central heating, ventilation, and air conditioning systems. The rule is intended both to reduce greenhouse gas emissions and save consumers money by increasing energy efficiency. However, according to DOE's calculations 86 percent of the benefits of this policy change are energy savings for consumers (DOE 2014, 38132-33, Tables I.3-I.4), ${ }^{1}$ indicating that the primary benefit of this rule is to reduce energy expenditures rather than carbon dioxide emissions. Valuations of consumer savings-especially savings that are far into the distant future, as is the case with this rule-can vary significantly depending on the discount rate used. Discount rates "discount" the value of future streams of benefits to present values so that benefits and costs can be compared in the same timeframes. This paper examines the sensitivity of DOE's anticipated benefits to different discount rates by drawing on

1. This figure is calculated by dividing the benefits that DOE lists for "Operating Cost Savings" at the 3 percent discount rate by the total benefits at the same discount rate listed in tables I.3 and I.4. 
DOE's analysis and existing economics literature on time preferences, consumer purchases of energy-using durables, and implicit consumer discount rates.

First, this paper discusses the practice of discounting costs and benefits in regulatory analysis and the importance of using appropriate discount rates. Second, it examines the discount rates that the Office of Management and Budget (OMB) recommends, and compares these rates with consumer discount rates for energy appliance purchases revealed in field studies, experiments, and elicitation. Third, it compares the net present value of DOE's furnace fan standards across a range of discount rates from the literature that represent the time preferences of low- and median-income households. Finally, this paper draws conclusions on the economic justifiability of DOE's rule based on the results of this sensitivity analysis.

\section{Discounting Regulatory Benefits}

DOE's rule applies to ten separate product classes of furnace fans and, according to its analysis (DOE 2014, 38131-32), will save a total of 3.99 quads of energy (or 3.99 quadrillion BTUs) over the first 30 years of implementation (2019 to 2048). The annualized energy savings amount to 1.3 percent of present annual residential energy consumption (EIA 2009), and the estimated energy savings in 2030 are equivalent to 0.3 percent of total residential energy use in 2012 (DOE 2014, 38132). DOE maintains that these energy savings will be a "significant conservation of energy" as the EPCA requires.

The primary benefit of this energy conservation is savings in energy expenditures by residential consumers, which comprise about 86 percent of the rule's total estimated benefits
(DOE 2014, 38132-33, Tables I.3-I.4). A secondary benefit of the rule is reductions in carbon emissions, which DOE estimates to be worth $\$ 312$ million annually (DOE 2014, 38133, Table I.4). However, without the benefits to consumers of reduced energy expenditures, the annualized costs of DOE's rule outweigh the annualized benefits by between $\$ 37$ million and $\$ 40$ million (DOE 2014, 38132, Table I.3). ${ }^{2}$ This indicates that DOE cannot justify its rule on environmental grounds alone, and relies on private benefits to residential consumers for its rule to pass the benefit-cost test.

According to DOE's analysis, consumers are expected to receive between $\$ 1,416$ million and $\$ 2,010$ million in annualized benefits from reduced energy bills (DOE 2014, 38202, Table V.31). In exchange for reduced long-term energy expenditures, the rule is expected to cause the prices of the most commonly purchased furnace fans to increase by between $\$ 65$ and \$154 per unit, depending on product class and current price. As a result of this rule, DOE expects 30 percent of consumers to experience a net cost and 56 percent of consumers to experience a net benefit resulting from reduced energy costs, with 14 percent of consumers experiencing no impact from the standards (DOE 2014, 38200, Table V.29).

To determine whether the long-term energy savings outweigh consumers' higher upfront equipment costs, future savings must be discounted to be compared with current costs. In its guidance to agencies on how to conduct regulatory analysis, the Office of Management and Budget

2. This figure is calculated by subtracting the benefit value for "Operating Cost Savings" discounted at 3 percent from the total benefits discounted at 3 percent. This sum is compared to the value for "Consumer Incremental Product Costs" discounted at 3 percent. The same calculation was conducted for the corresponding benefit and cost values discounted at 7 percent to provide a range of net costs. 
(OMB) explains:

Benefits and costs do not always take place in the same time period. When they do not, it is incorrect simply to add all of the expected net benefits or costs without taking account of when the [sic] actually occur. If benefits or costs are delayed or otherwise separated in time from each other, the difference in timing should be reflected in your analysis (OMB 2003, 31).

Because consumers receive the benefit of reduced energy bills over the entire estimated 22.6-year lifetimes of their furnace fans (DOE 2013, 64129), DOE must discount these benefits to make them comparable with the upfront costs resulting from the standards. Benefits expected in the future are diminished in this calculation because people generally prefer present consumption to future consumption; that is, they have positive time preferences (OMB 2003, 32). Discounting benefits and costs allows comparison between values occurring in different time periods by converting values to a common unit of measurement (OMB 1992, 4). In its analysis, DOE compares discounted benefits to discounted costs to calculate the net present value of the standards.

A very low discount rate implies that present consumption is not valued much more than future consumption, whereas a very high discount rate implies that future consumption has little value relative to present consumption. The appropriate rate by which to discount future benefits is not certain, and assuming a discount rate that is too high or too low can mischaracterize consumption preferences over time. This further complicates the calculation because a rule's total expected benefits can vary dramatically depending on the discount rate used to compare them to total expected costs. Using an inaccurate discount rate could jeopardize the economic justifiability of DOE's efficiency standard.

\section{OMB Guidelines on Discount Rates}

In 1992, OMB disseminated Circular A-94 to "provide[] specific guidance on the discount rates to be used in evaluating Federal programs whose benefits and costs are distributed over time" (OMB 1992, 3). This guidance establishes the procedures for agencies to follow when discounting benefits and costs.

In Circular A-94, OMB recommends that agencies use a default 7 percent discount rate when measuring the benefits of public investments and regulations because public investments and regulations displace both private investment and consumption. A 7 percent discount rate is appropriate in these cases because it "approximates the marginal pretax rate of return on an average investment in the private sector in recent years" (OMB 1992, 9) and thus approximates the opportunity cost of capital (OMB 2003 , 33). However, regulation does not always exclusively or primarily affect the allocation of capital, but instead may affect private consumers, in which cases a 7 percent discount rate may be too high (OMB 2003, 33). In such cases, OMB recommends that agencies use the "social rate of time preference," which is about 3 percent. This discount rate approximates average saving rates using the real rate of return on long-term government debt, such as 10-year Treasury notes (OMB 2003, 33), and thus can act as a proxy of how consumers value future consumption against current consumption.

Pursuant to OMB guidelines, DOE discounts at 3 and 7 percent 
to calculate the present value of its energy efficiency benefits, using a 3 percent discount rate for its primary benefit estimate. Discount rates of 3 and 7 percent put the annualized benefits of this rule at $\$ 2.328$ billion and $\$ 1.734$ billion, respectively, a range of \$594 million (DOE 2014, 38133, Table I.4). This large range indicates that the discount rate used in DOE's assessment is critically important in calculating the anticipated benefits of the regulation and in determining whether the regulation is economically justified, as the EPCA requires. However, consumers' actual discount rates are not homogenous, either across the population or across purchase types, and more variation in DOE's assessed benefits can be seen when using discount rates that better reflect actual consumer purchases of home appliances.

\section{Implicit Consumer Discount Rates for Appliance Purchases}

Many studies of implicit consumer discount rates use the purchase of energy-using durables (such as air conditioners, dishwashers, and refrigerators) to measure consumer time preferences (See, for example, Hausman 1979, Ruderman 1987, Dermot 1980). This is because these appliances have upfront costs that can potentially be offset by long-term energy savings, and there are often many available options with varying costs and levels of energy efficiency among which consumers may choose. Home heating and cooling systems specifically serve as useful examples of tradeoffs between upfront capital costs and longer-term operating cost savings (Hausman 1979, 34), making implicit discount rates more easily accessible. Because furnace fans are energy-using durables that provide consumers with "tradeoffs between capital costs and operating costs"
(Hausman 1979, 34), research on other energy-using home appliances is applicable to DOE's furnace fan rule.

Importantly, research on other energy-using home appliances shows that implicit discount rates are not stable, as OMB assumes, either over time or among purchase types (Frederick et al. 2002, 393). Based on the literature on field studies, Frederick et al. find implicit discount rates of between 17 and 300 percent for energy-using durables $(2002,384)$. Ruderman et al. find that consumer discount rates for furnaces range from 40 to 130 percent (Ruderman et al. 1987, 114). Newell and Siikamäki also find "considerable heterogeneity" for consumer discount rates for energy efficient appliances (Newell and Siikamäki 2015, 1), with standard deviations of 23 percent $(2015,3)$. These findings reinforce that consumers display significant variation in discount rates for purchasing residential appliances. The variance is so wide that DOE's use (and OMB's recommendation) of 3 and 7 percent seem unprepared to measure actual consumer benefits from energy efficiency standards.

For example, Ruderman et al. present evidence that implicit consumer discount rates for energy-using durables can be much higher than OMB's recommended discount rates and can vary widely by appliance (1987, 114-16). Frederick et al. find that Ruderman et al. measure discount rates of 102 percent for gas water heater purchases and 243 percent for electric water heaters (Frederick et al. 2002, 384). Because the focus of Ruderman et al.'s analysis is heating and cooling equipment, the findings are directly applicable to furnace fans. However, this paper excludes more extreme discount rates (e.g., 234 percent) in order to provide a more conservative estimate of the effects of implicit discount rates on calculating 
net benefits.

Discount rates for consumer appliances also vary by characteristics such as income, education, and race. In a working paper for the National Bureau of Economic Research, Newell and Siikamäki use econometric methods to find that consumers' actual discount rates are significantly related to individual and household characteristics, including education and race (Newell and Siikamäki 2015, 5-6). Newell and Siikamäki find that education matters significantly for individual discount rates, with discount rates consistently decreasing as education increases $(2015,5-6)$. They find that individuals with a college degree have discount rates approximately 13-14 percentage points lower than individuals with no college education (2015, 5-6). Income is also distinctly associated with discount rates (2015, 6). Based on these findings, $\mathrm{OMB}^{\prime} \mathrm{s}$ recommended discount rates do not seem well-prepared to analyze the effects of regulations on many consumers.

In his examination of the discount rates individuals apply when purchasing energy-using durables, Hausman notes that rates range from 5.1 to 89 percent for air conditioner purchases, depending on household income $(1979,53)$. Households with high incomes can afford to have lower discount rates, as they have more certain future streams of income; low-income households, on the other hand, do not benefit from the same certainty. This disparity means that "a result of [energy efficiency] standards is to place an implicit tax on those individuals who are thought to have the highest discount rates: the less well off. Thus efficiency standards can have an adverse income distribution effect" (Hausman 1979, 52).

As Hausman observes, the only individuals with actual dis- count rates that are approximate to the prevailing interest rates in credit markets are in the households with incomes higher than $\$ 160,844$ (adjusted for inflation, measured in 2013 dollars), which are the highest-income households included in Hausman's analysis (1979 53, Table 8). This implies that only high-income households are adequately represented by a 3 percent discount rate, the rate DOE uses to calculate the benefits of energy efficiency standards. Even median-income U.S. households have significantly higher discount rates of 27 percent for the purchase of energy-using durables, such as furnace fans (Hausman 1979, 53). It is worth noting that consumers reveal lower discount rates for air conditioners than for other energy-using durables such as furnaces (Ruderman et al. 1987, 114), meaning that median- and low-income households may have even higher discount rates for furnace fans than those found in Hausman's analysis.

The advantage of field studies is that they examine actual marketplace behavior, and are therefore directly applicable to consumer behavior for energy-using durables. This is in contrast to OMB's approach, which uses the real rate of return on long-term government debt, such as 10-year Treasury notes, to approximate consumer discount rates. While a 10-year Treasury note's interest rate is useful for analysis, it is not directly useful for understanding the tradeoffs that consumers make when purchasing durable energy-using goods. However, there may be other reasons why consumers' observed discount rates are so high, such as a lack of information-or an inability to adequately understand available information-about energy savings (Frederick et al. 2002, 386).

Other studies rely on elicita- 
tion and experiments to examine individual discount rates. For example, Andersen et al. find that individual discount rates have a mean of $25.3 \%$ and a median of $18.7 \%$, with a standard deviation of $14.1 \%$ (Andersen et al. 2006, 394). These rates are similar to those found by Harrison et al., who estimate mean and median discount rates of $24.2 \%$ and $24.5 \%$, respectively, and a standard deviation of $15.7 \%$ (Harrison et al. 2005). While informative, these studies are less relevant to the goals of this paper because they do not examine actual marketplace behavior and therefore indicate stated rather than revealed time preferences. In addition, they are general discount rates used by individuals, not discount rates used by individuals purchasing energy-using durables. However, they serve to reinforce that individuals have differing time preferences, and that typical discount rates are much higher than those used in DOE's analysis.

\section{Comparison of Regulatory Benefits across Discount Rates}

This analysis compares the net present value of $\mathrm{DOE}^{\prime} \mathrm{s}$ standards across a range of discount rates using information from DOE's final rule and the National Impact Analysis (NIA) Spreadsheet for Furnace Fans (EERE 2012). The calculations use DOE's projections for equipment stock, shipments, equipment lifetime, upfront cost, and operating cost savings. Although DOE's rule also relies on benefits resulting from reductions in carbon emissions, those benefits are relatively small, and are measured on a vastly different timeframe than operating cost savings; thus, they are excluded from this analysis. This analysis focuses on the effects of varying implicit consumer discount rates on the benefits and costs borne by consumers, which Table 1 displays. The furnace fan product classes this analysis considers are non-weatherized non-condensing gas furnace fans (NWGFnc), non-weatherized condensing gas furnace fans (NWGFc), weatherized gas furnace fans (WGF), and electric furnace/modular blower fans (EF). These product classes were chosen for the analysis because they are the most widely used residential furnace fans, comprising over 80 percent of projected furnace fan shipments through 2045 (EERE 2012).

\section{Table 1: Net Present Value Inputs}

\begin{tabular}{|c|c|}
\hline & \\
\hline $\begin{array}{l}\text { Upfront capital costs } \\
\text { - Increased product prices by product } \\
\text { class } \\
\text { - Shipments (number of units sold) by } \\
\text { product class }\end{array}$ & $\begin{array}{l}\text { - Price of energy } \\
\text { - Reductions in energy expenditure by } \\
\text { year by product class } \\
\text { - Lifetime of furnace fan by product } \\
\text { class }\end{array}$ \\
\hline \multicolumn{2}{|c|}{$\begin{array}{l}\text { Methodology: Increases in upfront capital costs and long-term operating cost savings } \\
\text { are derived from tables V.2, V.3, V.4, and V.6 of the final rule (DOE 2014, } \\
\text { 38184-85). Relevant values are those from efficiency level 4, the efficien- } \\
\text { cy level mandated in the final rule. Annual operating cost savings are } \\
\text { calculated by dividing average savings by furnace fan lifetime (in years) } \\
\text { Upfront capital costs are furnace fan product class installed cost, minus } \\
\text { the baseline installed cost. }\end{array}$} \\
\hline
\end{tabular}




\section{Table 2: Comparing Net Present Value of DOE's Standards at Different Discount Rates (2012 dollars)}

\begin{tabular}{|c|c|c|c|c|c|}
\hline \multirow{2}{*}{$\begin{array}{l}\text { Product } \\
\text { Class }\end{array}$} & \multicolumn{5}{|c|}{ Discount Rate } \\
\hline & $3 \%$ & $7 \%$ & $27 \%$ & $39 \%$ & $102 \%$ \\
\hline $\mathrm{EF}$ & $\$ 603,380,306$ & $\$ 281,289,811$ & $\$ 300,974$ & $-\$ 11,782,474$ & $-\$ 21,488,612$ \\
\hline WFG & $\$ 852,435,156$ & $\$ 335,484,663$ & $-\$ 78,098,414$ & $-\$ 91,114,981$ & $-\$ 77,180,732$ \\
\hline NWGFC & $\$ 2,584,004,688$ & $\$ 606,996,650$ & $-\$ 753,040,586$ & $-\$ 701,895,086$ & $-\$ 490,595,693$ \\
\hline NWGFnc & $\$ 2,892,828,906$ & $\$ 1,169,425,044$ & $-\$ 263,144,026$ & $-\$ 303,601,946$ & $-\$ 252,997,113$ \\
\hline Total & $\$ 6,932,649,056$ & $\$ 2,393,196,168$ & $-\$ 1,093,982,052$ & $-\$ 1,108,394,487$ & $-\$ 842,262,150$ \\
\hline
\end{tabular}

Source: Author's own calculations based on annual information provided in the Department of Energy's final rule and the National Impact Analysis (NIA) Spreadsheet for Furnace Fans (EERE 2012). See appendices A through D for individual product class NPV calculations.

Table 2 shows the five separate discount rates used to calculate the net present value of DOE's furnace fan rule. The net present value is calculated based on the first 15 years of the rule's implementation (from 2019 to 2033), but includes energy savings produced throughout the entire estimated product lifespan. All values are discounted to the first year of implementation and are measured in constant 2012 dollars. OMB's recommended discount rates of 3 and 7 percent are compared with three implicit discount rates for energy-using durables from existing field studies: Hausman's 27 percent, which is applicable to median-income households; Hausman's 39 percent, which is applicable to low-income households (1979, 53); and Ruderman et al.'s (1987) 102 percent, which is applicable to energy-using durables used in heating (Frederick et al. 2002, 384). Table 2 shows the results of this analysis.

As might be expected, discount rates of 3 and 7 percent result in large net benefits, with net present values of $\$ 6.9$ billion and $\$ 2.4$ billion, respectively. These gains are consistent across product classes. However, a 27 percent discount rate yields net costs with a net present value of about $-\$ 1.09$ billion, indicating that if Hausman's analysis is correct, median-income households do not benefit from these standards for most product classes. Interestingly, electric furnaces/modular blower fans do show a slight benefit to consumers at this implicit discount rate, indicating that DOE's rule may save median-income consumers money in this product class. The 39 percent and 102 percent discount rates show, unsurprisingly, that consumers will bear between $\$ 842$ million and $\$ 1.12$ billion in net costs as a result of the standards. All calculations assume that products last for their entire median lifetime. Therefore, this analysis may underestimate the number of consumers who bear a net cost from the standards based on early equipment failure. Further analysis shows that DOE's standards pose a net cost for any discount rate higher than $12 \%$ (See Appendix E). This breakeven discount rate is lower than the low-end discount rate for energy-using durables of $17 \%$ found by Frederick et al. $(2002,384)$, and the low-end discount rate for furnaces of $40 \%$ found by $\mathrm{Ru}$ derman et al. for furnaces $(1987,114)$. This indicates that even if DOE used the low-end of discount rates found in field studies, its standards would 
result in a net cost. This breakeven rate is also lower than both the mean and median individual discount rates measured by Andersen et al.: 25.3\% and $18.7 \%$, respectively (Andersen et al. 2006, 394). That is, even when using discount rates from the literature that are not based on field studies, DOE's rule results in net costs for consumers.

Energy efficiency rules are often touted for their environmental benefits, such as reducing climate change. As mentioned earlier in this paper, DOE values the reduction in carbon dioxide emissions at $\$ 312$ million per year for these standards. However, if consumers don't benefit from longer-term reduced operating costs, the annualized costs of DOE's rule outweigh the benefits by between $\$ 37$ million and \$40 million annually (DOE 2014, 38133, Table I.4), which indicates that DOE cannot justify its rule on environmental grounds alone.

\section{Conclusion}

DOE's energy efficiency standard for furnace fans meets the statutory criterion of "economically justified" under two discount rates examined in this paper: 3 and 7 percent, the discount rates recommended in $\mathrm{OMB}^{\prime}$ s guidelines. However, these discount rates are not well-equipped to represent the significant heterogeneity in consumer discount rates for purchases of energy-using durables. According to Hausman's analysis, OMB's recommended rates most closely represent the implicit discount rates used by high-income households $(1979,53)$. However, DOE's rule is not economically justified when discount rates that apply to low- or medianincome households, which range from 27 to 102 percent, are used. When these higher discount rates are used, the net present value of DOE's rule ranges from $-\$ 842$ million to $-\$ 1.12$ billion over the first 15 years of implementation. Indeed, DOE's rule is likely to yield net costs for any discount rate above $12 \%$, well below the mean and median individual discount rates identified in the literature. If these higher discount rates accurately represent the implicit discount rates used by low- and median-income households, low- and median-income consumers do not receive any benefit from DOE's standards and instead incur net costs. These costs are especially high for low-income households and individuals with high discount rates, indicating that DOE's efficiency standard for furnace fans acts as a transfer payment from low-income households to high-income households. 
Policy Perspectives | Volume 22

\section{Appendices}

Appendix A: Net Benefits of DOE's Energy Efficiency Standards for NonWeatherized, Non-Condensing Gas Furnace Fans

\begin{tabular}{|c|c|c|c|c|c|}
\hline \multirow{2}{*}{ Year } & \multicolumn{5}{|c}{ Net Present Value Discounted to 2019 } \\
\cline { 2 - 6 } & $3 \%$ & $7 \%$ & $27 \%$ & $39 \%$ & $102 \%$ \\
\hline $\mathbf{2 0 1 9}$ & $\$ 208,675,467$ & $\$ 96,505,777$ & $-\$ 75,351,606$ & $-\$ 101,768,536$ & $-\$ 139,060,806$ \\
\hline $\mathbf{2 0 2 0}$ & $\$ 226,346,143$ & $\$ 112,654,937$ & $-\$ 40,920,763$ & $-\$ 56,465,207$ & $-\$ 57,386,414$ \\
\hline $\mathbf{2 0 2 1}$ & $\$ 219,691,172$ & $\$ 105,255,109$ & $-\$ 32,211,929$ & $-\$ 40,610,922$ & $-\$ 28,412,376$ \\
\hline $\mathbf{2 0 2 2}$ & $\$ 214,079,532$ & $\$ 98,732,281$ & $-\$ 25,457,325$ & $-\$ 29,324,311$ & $-\$ 14,111,814$ \\
\hline $\mathbf{2 0 2 3}$ & $\$ 209,431,401$ & $\$ 92,977,801$ & $-\$ 20,198,212$ & $-\$ 21,257,730$ & $-\$ 7,039,395$ \\
\hline $\mathbf{2 0 2 4}$ & $\$ 205,119,739$ & $\$ 87,659,376$ & $-\$ 16,043,979$ & $-\$ 15,427,835$ & $-\$ 3,515,498$ \\
\hline $\mathbf{2 0 2 5}$ & $\$ 200,604,521$ & $\$ 82,524,914$ & $-\$ 12,725,617$ & $-\$ 11,180,485$ & $-\$ 1,753,097$ \\
\hline $\mathbf{2 0 2 6}$ & $\$ 195,568,620$ & $\$ 77,445,642$ & $-\$ 10,061,687$ & $-\$ 8,076,841$ & $-\$ 871,466$ \\
\hline $\mathbf{2 0 2 7}$ & $\$ 189,698,348$ & $\$ 72,312,738$ & $-\$ 7,915,324$ & $-\$ 5,805,349$ & $-\$ 431,023$ \\
\hline $\mathbf{2 0 2 8}$ & $\$ 183,733,680$ & $\$ 67,420,735$ & $-\$ 6,217,666$ & $-\$ 4,166,544$ & $-\$ 212,869$ \\
\hline $\mathbf{2 0 2 9}$ & $\$ 178,250,929$ & $\$ 62,963,659$ & $-\$ 4,892,197$ & $-\$ 3,898,038$ & $-\$ 105,303$ \\
\hline $\mathbf{2 0 3 0}$ & $\$ 173,282,210$ & $\$ 58,920,385$ & $-\$ 3,857,089$ & $-\$ 2,157,675$ & $-\$ 52,197$ \\
\hline $\mathbf{2 0 3 1}$ & $\$ 168,157,813$ & $\$ 55,040,465$ & $-\$ 3,035,682$ & $-\$ 1,551,571$ & $-\$ 25,828$ \\
\hline $\mathbf{2 0 3 2}$ & $\$ 162,674,054$ & $\$ 51,285,928$ & $-\$ 2,373,298$ & $-\$ 1,109,385$ & $-\$ 12,716$ \\
\hline $\mathbf{2 0 3 3}$ & $\$ 157,515,277$ & $\$ 47,725,297$ & $-\$ 1,881,651$ & $-\$ 801,517$ & $-\$ 6,311$ \\
\hline Total & $\$ 2,892,828,906$ & $\$ 1,169,425,044$ & $-\$ 263,144,026$ & $-\$ 303,601,946$ & $-\$ 252,997,113$ \\
\hline
\end{tabular}




\begin{tabular}{|c|c|c|c|c|c|}
\hline \multirow[t]{2}{*}{ Year } & \multicolumn{5}{|c|}{ Net Present Value Discounted to 2019} \\
\hline & $3 \%$ & $7 \%$ & $27 \%$ & $39 \%$ & $102 \%$ \\
\hline 2019 & $\$ 167,662,637$ & $\$ 29,854,641$ & $-\$ 181,283,695$ & $-\$ 213,738,666$ & $-\$ 259,554,725$ \\
\hline 2020 & $\$ 193,081,618$ & $\$ 55,601,825$ & $-\$ 121,301,619$ & $-\$ 134,444,802$ & $-\$ 115,453,963$ \\
\hline 2021 & $\$ 188,944,723$ & $\$ 52,376,483$ & $-\$ 96,270,658$ & $-\$ 97,490,047$ & $-\$ 57,608,761$ \\
\hline 2022 & $\$ 185,559,914$ & $\$ 69,948,746$ & $-\$ 76,679,070$ & $-\$ 70,946,683$ & $-\$ 28,848,537$ \\
\hline 2023 & $\$ 182,930,936$ & $\$ 46,988,936$ & $-\$ 61,307,462$ & $-\$ 51,827,172$ & $-\$ 14,501,490$ \\
\hline 2024 & $\$ 180,615,764$ & $\$ 44,659,880$ & $-\$ 49,092,521$ & $-\$ 37,918,263$ & $-\$ 7,300,742$ \\
\hline 2025 & $\$ 178,065,815$ & $\$ 42,383,411$ & $-\$ 39,253,080$ & $-\$ 27,701,020$ & $-\$ 3,670,099$ \\
\hline 2026 & $\$ 175,103,095$ & $\$ 40,120,157$ & $-\$ 31,305,491$ & $-\$ 20,185,126$ & $-\$ 1,840,250$ \\
\hline 2027 & $\$ 171,482,698$ & $\$ 37,821,831$ & $-\$ 24,864,544$ & $-\$ 14,648,069$ & $-\$ 918,944$ \\
\hline 2028 & $\$ 169,815,654$ & $\$ 37,037,528$ & $-\$ 19,436,982$ & $-\$ 10,490,450$ & $-\$ 454,005$ \\
\hline 2029 & $\$ 164,519,855$ & $\$ 33,623,851$ & $-\$ 15,690,816$ & $-\$ 7,716,551$ & $-\$ 229,223$ \\
\hline 2030 & $\$ 161,503,921$ & $\$ 31,773,544$ & $-\$ 12,492,339$ & $-\$ 5,613,199$ & $-\$ 114,739$ \\
\hline 2031 & $\$ 158,301,398$ & $\$ 29,979,251$ & $-\$ 9,930,679$ & $-\$ 4,076,942$ & $-\$ 57,345$ \\
\hline 2032 & $\$ 154,757,829$ & $\$ 28,212,535$ & $-\$ 7,873,727$ & $-\$ 2,953,417$ & $-\$ 28,586$ \\
\hline 2033 & $\$ 151,658,831$ & $\$ 26,614,029$ & $-\$ 6,257,904$ & $-\$ 2,144,679$ & $-\$ 14,284$ \\
\hline Total & $\$ 2,584,004,688$ & $\$ 606,996,650$ & $-\$ 753,040,586$ & $-\$ 701,895,086$ & $-\$ 490,595,693$ \\
\hline
\end{tabular}




\section{Appendix C: Net Benefits of DOE's Energy Efficiency Standards for Weatherized Gas Furnace Fans}

\begin{tabular}{|c|c|c|c|c|c|}
\hline \multirow{2}{*}{ Year } & \multicolumn{5}{|c}{ Net Present Value Discounted to 2019 } \\
\cline { 2 - 6 } & $3 \%$ & $7 \%$ & $27 \%$ & $39 \%$ & $102 \%$ \\
\hline 2019 & $\$ 106,198,588$ & $\$ 26,797,910$ & $-\$ 22,664,525$ & $-\$ 30,857,429$ & $-\$ 42,562,831$ \\
\hline 2020 & $\$ 62,052,137$ & $\$ 32,040,326$ & $-\$ 12,033,164$ & $-\$ 16,900,760$ & $-\$ 17,436,531$ \\
\hline 2021 & $\$ 60,244,793$ & $\$ 29,944,230$ & $-\$ 9,474,932$ & $-\$ 12,158,820$ & $-\$ 8,631,946$ \\
\hline $\mathbf{2 0 2 2}$ & $\$ 58,680,781$ & $\$ 28,076,500$ & $-\$ 7,484,900$ & $-\$ 8,775,871$ & $-\$ 4,287,172$ \\
\hline $\mathbf{2 0 2 3}$ & $\$ 57,358,736$ & $\$ 26,418,010$ & $-\$ 5,933,667$ & $-\$ 6,356,475$ & $-\$ 2,136,783$ \\
\hline $\mathbf{2 0 2 4}$ & $\$ 56,145,625$ & $\$ 24,892,579$ & $-\$ 4,710,565$ & $-\$ 4,610,575$ & $-\$ 1,066,504$ \\
\hline $\mathbf{2 0 2 5}$ & $\$ 54,970,385$ & $\$ 23,460,443$ & $-\$ 3,740,412$ & $-\$ 3,344,956$ & $-\$ 532,429$ \\
\hline $\mathbf{2 0 2 6}$ & $\$ 53,754,366$ & $\$ 22,083,841$ & $-\$ 2,966,456$ & $-\$ 2,423,806$ & $-\$ 265,480$ \\
\hline $\mathbf{2 0 2 7}$ & $\$ 52,442,919$ & $\$ 20,739,638$ & $-\$ 2,347,170$ & $-\$ 1,752,239$ & $-\$ 132,066$ \\
\hline $\mathbf{2 0 2 8}$ & $\$ 51,147,747$ & $\$ 19,471,270$ & $-\$ 1,856,597$ & $-\$ 1,266,355$ & $-\$ 65,678$ \\
\hline $\mathbf{2 0 2 9}$ & $\$ 49,982,201$ & $\$ 18,316,251$ & $-\$ 1,471,431$ & $-\$ 916,994$ & $-\$ 32,726$ \\
\hline $\mathbf{2 0 3 0}$ & $\$ 48,950,638$ & $\$ 17,267,641$ & $-\$ 1,168,736$ & $-\$ 665,476$ & $-\$ 16,343$ \\
\hline $\mathbf{2 0 3 1}$ & $\$ 47,896,906$ & $\$ 16,264,307$ & $-\$ 927,468$ & $-\$ 482,507$ & $-\$ 8,154$ \\
\hline $\mathbf{2 0 3 2}$ & $\$ 46,785,634$ & $\$ 15,293,049$ & $-\$ 734,747$ & $-\$ 349,246$ & $-\$ 4,061$ \\
\hline $\mathbf{2 0 3 3}$ & $\$ 45,823,700$ & $\$ 14,418,668$ & $-\$ 583,645$ & $-\$ 253,473$ & $-\$ 2,028$ \\
\hline Total & $\$ 852,435,156$ & $\$ 335,484,663$ & $-\$ 78,098,414$ & $-\$ 91,114,981$ & $-\$ 77,180,732$ \\
\hline
\end{tabular}


Appendix D: Net Benefits of DOE's Energy Efficiency Standards for Electric Furnaces/Modular Blower Fans

\begin{tabular}{|c|c|c|c|c|c|}
\hline \multirow{2}{*}{ Year } & \multicolumn{5}{|c}{ Net Present Value Discounted to 2019 } \\
\cline { 2 - 6 } & $3 \%$ & $7 \%$ & $27 \%$ & $39 \%$ & $102 \%$ \\
\hline $\mathbf{2 0 1 9}$ & $\$ 39,537,601$ & $\$ 19,706,258$ & $-\$ 13,467,132$ & $-\$ 18,961,937$ & $-\$ 26,812,497$ \\
\hline $\mathbf{2 0 2 0}$ & $\$ 46,256,704$ & $\$ 28,773,459$ & $\$ 6,138,752$ & $\$ 4,284,000$ & $\$ 2,999,846$ \\
\hline $\mathbf{2 0 2 1}$ & $\$ 45,210,582$ & $\$ 27,071,414$ & $\$ 4,866,077$ & $\$ 3,102,682$ & $\$ 1,495,031$ \\
\hline $\mathbf{2 0 2 2}$ & $\$ 44,398,804$ & $\$ 25,591,489$ & $\$ 3,875,642$ & $\$ 2,257,828$ & $\$ 748,630$ \\
\hline $\mathbf{2 0 2 3}$ & $\$ 43,449,885$ & $\$ 23,220,715$ & $\$ 1,551,300$ & $\$ 437,018$ & $\$ 138,467$ \\
\hline $\mathbf{2 0 2 4}$ & $\$ 42,513,364$ & $\$ 21,759,895$ & $\$ 1,141,951$ & $\$ 266,007$ & $\$ 65,845$ \\
\hline $\mathbf{2 0 2 5}$ & $\$ 42,007,334$ & $\$ 20,697,119$ & $\$ 915,126$ & $\$ 194,767$ & $\$ 33,175$ \\
\hline $\mathbf{2 0 2 6}$ & $\$ 41,394,263$ & $\$ 19,632,625$ & $\$ 731,357$ & $\$ 142,217$ & $\$ 16,669$ \\
\hline $\mathbf{2 0 2 7}$ & $\$ 39,021,532$ & $\$ 15,951,316$ & $-\$ 1,393,988$ & $-\$ 1,114,874$ & $-\$ 87,495$ \\
\hline $\mathbf{2 0 2 8}$ & $\$ 38,269,850$ & $\$ 15,059,218$ & $-\$ 1,108,779$ & $-\$ 810,216$ & $-\$ 43,755$ \\
\hline $\mathbf{2 0 2 9}$ & $\$ 37,583,203$ & $\$ 14,236,161$ & $-\$ 883,111$ & $-\$ 589,604$ & $-\$ 21,910$ \\
\hline $\mathbf{2 0 3 0}$ & $\$ 36,970,047$ & $\$ 13,480,393$ & $-\$ 704,539$ & $-\$ 429,773$ & $-\$ 10,990$ \\
\hline $\mathbf{2 0 3 1}$ & $\$ 36,309,496$ & $\$ 12,744,600$ & $-\$ 561,189$ & $-\$ 312,775$ & $-\$ 5,504$ \\
\hline $\mathbf{2 0 3 2}$ & $\$ 35,550,367$ & $\$ 12,011,674$ & $-\$ 445,622$ & $-\$ 82,706$ & $-\$ 2,748$ \\
\hline $\mathbf{2 0 3 3}$ & $\$ 34,907,272$ & $\$ 11,353,475$ & $-\$ 354,872$ & $-\$ 165,109$ & $-\$ 1,376$ \\
\hline Total & $\$ 603,380,306$ & $\$ 281,289,811$ & $\$ 300,974$ & $-\$ 11,782,474$ & $-\$ 21,488,612$ \\
\hline
\end{tabular}


Policy Perspectives | Volume 22

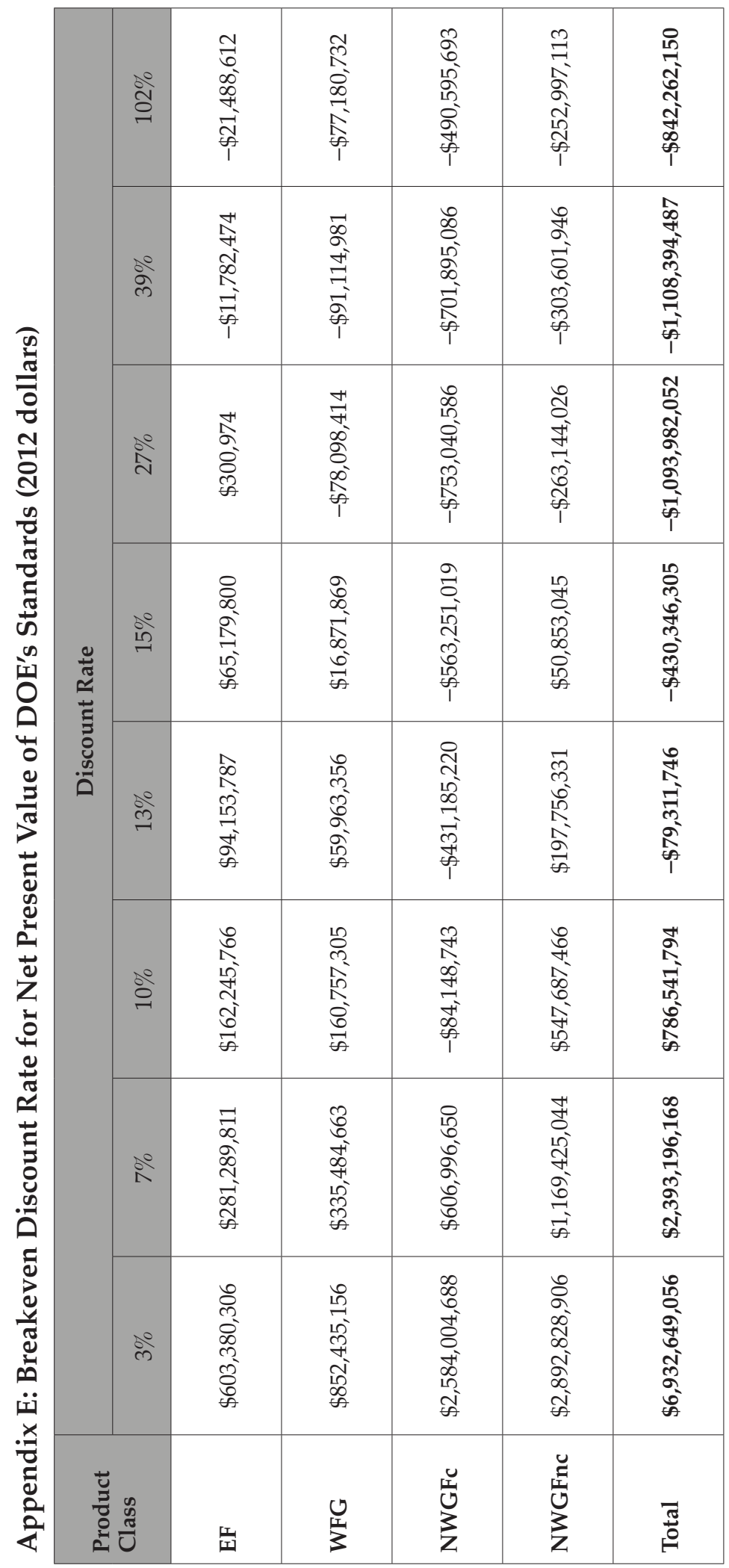




\section{References}

Andersen, Steffen, Glenn W. Harrison, Morton I. Lau, and E. Elisabet Ruström. 2006. “Elicitation Using Multiple Price List Formats." Exp Econ 9:383405.

DOE (Department of Energy). 2013. “Energy Conservation Program for Consumer Products: Energy Conservation Standards for Residential Furnace Fans." 78 Fed. Reg. 64068-64139.

2014. "Energy Conservation Program for Consumer Products: Energy Conservation Standards for Residential Furnace Fans." 79 Fed. Reg. 38129-38211.

EERE (Energy Efficiency and Renewable Energy Office). 2012. National Impact Analysis (NIA) Spreadsheet for Furnace Fans. http: / / www.regulations. gov/\#!documentDetail;D=EERE-2010-BT-STD-0011-0039. Washington, DC.

EIA (Energy Information Administration). 2009. Residential Energy Consumption Survey (RECS). Table CE1.1: Summary Household Site Consumption and Expenditures in the U.S. - Totals and Intensities, 2009. http: / / www.eia.gov / consumption/ residential / data/2009/index. $\mathrm{cfm}$ ?view=consumption\#summary. Washington, DC.

Frederick, Shane, George Loewenstein, and Ted O'Donoghue. 2002. “Time Discounting and Time Preference: A Critical Review." Journal of Economic Literature 40(2):351-401.

Gately, Dermot. 1980. "Individual Discount Rates and the Purchase and Utilization of Energy Using Durables: Comment." The Bell Journal of Economics 11:373-74.

Harrison, Glenn W, Morten Igel Lau, E. Elisabet Rutström, and Melonie B. Sullivan. 2005. "Eliciting risk and time preferences using field experiments: Some methodological issues." In Carpenter, J., Harrison, G.W., \& List, J.A., (Eds.), Field Experiments in Economics (Greenwich, CT: JAI Press, Research in Experimental Economics, Volume 10).

Hausman, Jerry A. 1979. "Individual Discount Rates and the Purchase and Utilization of Energy-Using Durables." The Bell Journal of Economics 10(1):33-54.

Newell, Richard G., and Juha V. Siikamäki. 2015. "Individual Time Preferences and Energy Efficiency." National Bureau of Economic Research Working Paper 20969.

OMB (Office of Management and Budget). 1992. "Circular A-94: Guidelines and Discount Rates for Benefit-Cost Analysis of Federal Programs." 2003. "Circular A-4: Regulatory Analysis."

Ruderman, Henry, Mark Levine, and James McMahon. 1987. "The Behavior of the Market for Energy Efficiency in Residential Appliances Including Heating and Cooling Equipment." The Energy Journal 8(1):101-24.

Sofie E. Miller is a Master of Public Policy student at the George Washington University focusing on regulatory policy and quantitative policy analysis. She is also a Senior Policy Analyst at the George Washington University Regulatory Studies Center, where her research portfolio includes economic analysis of energy efficiency standards, analysis of regulatory benefits, use of benefit-cost 


\section{Policy Perspectives | Volume 22}

analysis by agencies, retrospective review of existing rules, and the regressive effects of regulations. Sofie has submitted public comments to federal agencies on regulations spanning every issue from airline passenger protections to foodborne illnesses and everything in between. Upon completing her MPP, she intends to continue her work on regulatory analysis within academia and, eventually, the federal government.

The author thanks her faculty reviewer, Professor Susan Dudley, for her continued mentorship, encouragement, and guidance throughout this research project and many others. Sofie also thanks Editors-in-Chief Anne Kruse and Christine Mellen and Associate Editor Marisa Kanof, all of whose thoughtful insights and discernment vastly improved the quality of this paper. The author benefitted greatly from the attention to detail displayed by the entire editorial team, and commends them for their dedication and professionalism. Finally, the author thanks her parents for instilling in her the ability to think critically, and her husband, Chad M. Reese, for believing that she can accomplish anything she sets her mind to. (He isn't wrong.) 